\title{
ST Elevation Pericarditis by ECG Finding
}

National Cancer Institute

\section{Source}

National Cancer Institute. ST Elevation Pericarditis by ECG Finding. NCI Thesaurus. Code C71029.

An electrocardiographic finding of ST elevation which is concave upwards, and which is often accompanied by PR segment depression. (CDISC) 